\title{
Lloyd F. Mayer, MD: a remembrance
}

\author{
CO Elson ${ }^{1}$, EB Chang ${ }^{2}$ and SA Lira ${ }^{3}$
}

\section{$\mathrm{L}$}

loyd Mayer lost a battle against brain cancer on 5 September 2013. At the Dorothy and David Merksamer Professor of Medicine endowed chair and was chief of the Division of Clinical Immunology at the Icahn School of Medicine at Mount Sinai in New York. He was also Co-Director of Mount Sinai's Immunology Institute, which he had helped to found. A native of New York, Lloyd received his MD from Mount Sinai School of Medicine, trained in internal medicine at New York University, and returned to Mount Sinai for his fellowship in gastroenterology. Following that, he spent three years pursuing immunology research as a postdoctoral fellow in Henry Kunkel's laboratory at Rockefeller University. While in the Kunkel lab and afterward, Lloyd utilized a technique to generate human T-cell hybridomas to identify factors and cytokines that stimulated B cells. ${ }^{1}$ This led to the discovery that some individuals with common variable immunodeficiency have defects in T-cell cytokines rather than defects in B cells. ${ }^{2}$ Common to all his work-whether in immunodeficiency, mucosal immunology, or inflammatory bowel disease (IBD) — was a primary focus on humans. His talents were quickly recognized at Mount Sinai, and one year after joining the faculty he was named chief of the Division of Clinical Immunology.

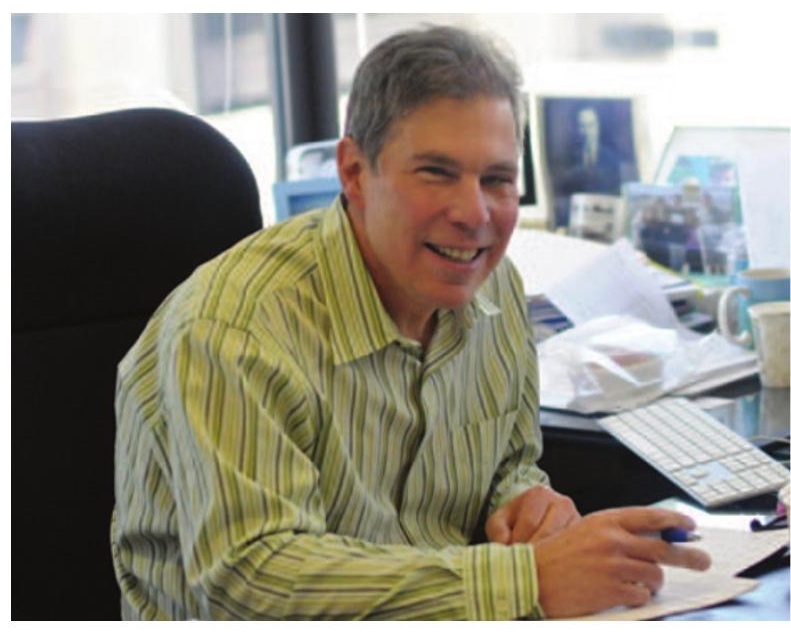

Lloyd F. Mayer, MD

Lloyd was a charter member of the Society for Mucosal Immunology (SMI), attending most of the International Congresses and co-organizing the 2005 Congress in Boston. He served the SMI in many other roles, including as a member of the editorial board of this journal and the Board of Councilors. Lloyd led by example at Mount Sinai as well as in all the organizations in which he was active, showing his passion for the field, the joy he took in his work, generosity with his time and expertise, and his openness and willingness to help others, either as a collaborator or as a mentor to young investigators. 
Lloyd received many honors for his substantive academic, clinical, and research achievements, which have been detailed elsewhere. ${ }^{3}$ Below we present vignettes of our personal interactions that help to explain why we already miss him. Undoubtedly, many other colleagues could contribute similar reminiscences.

\section{Charles Elson}

met Lloyd at a mucosal immunology

meeting that I organized in Fort

Lauderdale in the 1980s. He had just finished postdoctoral fellowship training in immunology with Henry Kunkel at Rockefeller University and was establishing his laboratory as a faculty member at Mount Sinai, his alma mater. Lloyd wanted to learn how to isolate cells from human intestinal resections, which my lab was doing at the time. I invited him to visit and learn the technique firsthand. During the visit, he asked about the condition of the epithelial cells (ECs). I had been discarding these cells, assuming that they died rapidly. We went back to the lab, and, much to my surprise, ECs were readily identifiable under the microscope and were mostly viable. Lloyd subsequently did pioneering studies on the immunologic properties of intestinal ECs (IECs), which led to a change in paradigm and recognition that IECs are an active partner with the intestinal immune system and critical in maintaining mucosal homeostasis. He was fond of crediting me with getting him started, but the vision, curiosity, and drive to explore this new area were all his. We remained friends and colleagues over the following three decades.

I subsequently visited Mount Sinai to learn how to generate human T-cell hybridomas. Lloyd picked me up during morning rush hour, and I was treated to his "shortcut" on and off the clogged expressway, through factory areas and railyards, which only a native New Yorker could understand. My other main memory of that day was witnessing the art of performing a fusion by centrifuging the lymphocytes using an ancient, floormodel centrifuge with the lid open. On the inside of the lid was a warning to remove one's necktie before turning on the procedure-I am sure the warning was based on an unfortunate experience. No doubt such special moments will never occur again in this era of lab-safety audits. Lloyd was clearly at home in his lab and worked at the bench himself, despite all his other responsibilities.

Over the years, Lloyd and I shared our latest data and projects, seeking out and trusting each other's comments and criticisms, which were always constructive. I recall walking with Lloyd in Berlin, where we were attending a mucosal immunology meeting. I mentioned my plans for a project on oral tolerance in humans and learned that he had already been collaborating with others on such a project. He shared details of the protocol with me so that we could coordinate the effort and ensure that the data from the two groups would be compatible. Using KLH as the test antigen, my lab reported on the induction of selective T-cell, but not B-cell, tolerance after antigen feeding of healthy humans. ${ }^{4}$ Lloyd and his collaborators subsequently discovered a defect of such oral tolerance in individuals with IBD. ${ }^{5,6}$

\section{Gene Chang}

v met Lloyd in 1985, when I was visiting Mount Sinai Medical Center as a potential faculty recruit. Lloyd could easily come across as intimidating just by virtue of his intelligence and nimble mind, but he was actually warm, approachable, and unpretentious. $\mathrm{He}$ 
was engaging and genuine. At the time, our research interests seemed to be miles apart, he being a mucosal immunologist and I an epithelial transport physiologist. Yet we immediately bonded because of his infectious enthusiasm for science, and in time we formed a relationship that led to productive interactions, mutual respect, and a lifelong friendship.

Lloyd was then just beginning to investigate the role of gut epithelium as accessory cells in an immune response, functioning as non-professional antigenpresenting cells for $\mathrm{CD}^{+}$and $\mathrm{CD} 8^{+} \mathrm{T}$ cells. ${ }^{7-10}$ He was intrigued by the delicate balance between immune activation and tolerance, and hypothesized that the gut epithelium had an essential role in directing the gut immune state in a dynamic way that was relevant to both health and disease. This was a radical departure from the then-prevailing dogma that the IEC was merely the passive partner or innocent bystander of activated immune processes associated with diseases like IBD. As Lloyd and others subsequently showed, the mucosal barrier was in fact highly active from an immunological point of view. He showed that IECs, in addition to processing antigens, secrete a variety of cytokines and chemokines ${ }^{11}$ that are now known to be important mediators of immune homeostasis. These ideas greatly influenced our own thinking in the area and drew my lab into the area of IBD and immune regulation of IECs.

With Lloyd, we pursued the possibility that gut epithelial-immune interactions might be bidirectional and that immune cells were involved in the regulation of IEC function. This notion was confirmed when we found that several proinflammatory cytokines and mediators did indeed physiologically regulate intestinal epithelial transport and barrier functions. ${ }^{12}$ For us, this led to a conceptual shift from thinking of cell systems in isolation to integration of systems in the physiological and pathophysiological contexts. In this regard, Lloyd was a pioneer because he was among the first to recognize the importance of studying epithelial and immune cell interactions in human pathology samples. He mastered the art of isolating and cultivating human IECs and developed novel coculture systems that provided key insights into the pathogenesis of IBD. This led to several important discoveries, such as that of a novel CD8 ligand expressed by IECs, gp180, that appeared to be defective in IBD. ${ }^{13}$ Also, he found that IECs from patients with IBD, but not healthy controls, express costimulatory molecules B7h and B7-H1. ${ }^{14}$ These discoveries are being applied by many laboratories to investigate the cause and mechanistic basis of IBD using systems analysis and integration.

In the course of his brilliant career, Lloyd mentored numerous outstanding trainees who have become leaders in the field in their own right. His style was leading by example, instilling in them the same passion and excitement for scholarship and discovery that he had. Lloyd's legacy will continue through these individuals, as they carry his torch into the future.

\section{Sergio Lira}

M y first interaction with Lloyd happened over the phone-he invited me to give a talk at Mount Sinai. My first meeting with him happened a few minutes before the talk, while I was setting up my computer. $\mathrm{He}$ introduced himself, and I was surprised at how young he looked. He was going to turn 50 but looked 35. After the talk, we went to his very messy office, decorated 
with piles of paper, a couple of nice posters (yes, his wife, Jill, put them up), a picture of Burrill Crohn, pictures of his family, and, on his desk, a fake Häagen-Dazs ice cream cup melting onto a floppy disk. On a reflex, I reached to move it. He laughed. We talked for a few minutes, and then he asked me, out of the blue, if I would consider a position in the Immunobiology Center, which he directed. That came as a shock-I thought that I was giving a talk, not interviewing for a position. I drove home to New Jersey thinking about his offer. I had been in pharma for 10 years. This would be quite a move: new world, grants to write, relationships to build, starting all over again. I had no idea what a major medical center in New York City would look like. But I liked Lloyd, we really connected that day, and I trusted him instinctively. I took the job, and a few weeks later we went out to celebrate. On our way to the restaurant, he ran six red lights. Years later he would repeat the feat while driving to a FedEx office 15 minutes before the deadline for submission of our program project grant. And this was after his neurosurgery. I trusted him.

I joined Mount Sinai in July 2002. I felt at home immediately, but it took me some time to adapt to the new city. Lloyd helped me a lot during this phase: he corrected my first grant applications, introduced me to people, opened doors to me, and taught me how to cross a New York street.

I quickly realized that everybody loved and respected him. He seemed busy, but he always had time. He always had time for the faculty and was always present in anything that had to do with immunology. Lesson number 1: show up. Lesson number 2: help. Number 3: if things are not the way you want, don't complain; move on.

When we first met, I had no idea of his numerous contributions to immunology and his standing in the gastroenterology field. This changed quickly. He invariably asked questions during seminars, sometimes about very basic stuff. And he had always a word of encouragement, a suggestion.

He was a very generous man, and he insisted on giving people a chance. He had the ability to reach out and help. His efforts went beyond his group, beyond his institution. He had a major impact on national and international research programs, helping to fund and structure them. Lloyd had international fame and recognition, but was a humble, funny, and unpretentious guy.

In 2007, our dean asked us to codirect the newly formed Immunology Institute. We were very excited with the new challenge. By then we had been working together for a few years and we were in sync on many things, despite our different styles. He was always looking for opportunities for our faculty. He was tireless. He would carry a very heavy briefcase, stuffed with papers, grants, reports. On the plane, he was always working-or reading the sports page. Getting to the plane was another story: invariably five minutes before takeoff. How he did it remains a mystery to me.

I don't remember exactly when we started collaborating scientifically, but it was inevitable. We talked about medicine and disease quite a bit. Our first paper together was published in 2008, with Maria Abreu. ${ }^{15}$ It was followed by others that looked at chemokine regulation of leukocyte trafficking into the gut. ${ }^{16}$ We subsequently worked together on many papers and grants. Always a source of inspiration and encouragement, he brought me into the mucosal immunology field. He had an encyclopedic knowledge of the topic, and if he did not know something, he knew who would know. 
A man with so many talents and qualities generated a very positive atmosphere around him. When he got sick, many people came to see him. His trainees came from far away, multiple times. Friends from all over the country dropped by. I lost track of how many times people contacted me asking after him. And throughout his disease, he was always smiling, being positive, reviewing grants, helping. No self-pity, no complaints. At a time when most people would retire at home, he was here meeting with us, discussing science. When he was admitted to the hospital, he kept saying: "I have to do it." One day I asked him what he meant by that and ran a few possibilities by him. When I got to "Do you mean go to the lab?," he nodded. It was remarkable. The only thing more remarkable was his devotion to his family, which I witnessed closely during the last year of his life.

\section{Our colleague}

Among the most rewarding aspects of an investigative career are the relationships one develops with colleagues, trainees, and others along the way. Scientific investigation is difficult. Sharing the journey with like-minded individuals not only increases productivity but also is one of the most enjoyable aspects of research and teaching. Fostering such interactions is the purpose of scientific organizations such as the SMI. We believe that Lloyd epitomized the qualities we should aspire to, such as collegiality, sharing of talents, willingness to help others, and a deep curiosity and desire to understand the complexity that is mucosal immunology.

(C) 2014 Society for Mucosal Immunology
1. Mayer, L., Fu, S.M., Cunningham-Rundles, C. \& Kunkel, H.G. Polyclonal immunoglobulin secretion in patients with common variable immunodeficiency using monoclonal $B$ cell differentiation factors. J. Clin. Invest. 74, 2115-2120 (1984).

2. Mayer, L., Fu, S.M. \& Kunkel, H.G. Human T cell hybridomas secreting factors for IgA-specific help, polyclonal B cell activation, and B cell proliferation. J. Exp. Med. 156, 1860-1865 (1982).

3. Sands, B.E. \& Itzkowitz, S.H. In memoriam. Gastroenterology 145, 1169-1170 (2013).

4. Husby, S., Mestecky, J., Moldoveanu, Z., Holland, S. \& Elson, C.O. Oral tolerance in humans. T cell but not B cell tolerance after antigen feeding. J. Immunol. 152 , 4663-4670 (1994).

5. Kraus, T.A., Toy, L., Chan, L., Childs, J. \& Mayer, L. (2004). Failure to induce oral tolerance to a soluble protein in patients with inflammatory bowel disease. Gastroenterology 126, 1771-1778 (2004).

6. Kraus, T.A., Cheifetz, A., Toy, L., Meddings, J.B. \& Mayer L. (2006). Evidence for a genetic defect in oral tolerance induction in inflammatory bowel disease. Inflamm. Bowel. Dis. 12, 82-88 (2006).

7. Mayer, L. \& Shlien, R. Evidence for function of la molecules on gut epithelial cells in man. J. Exp. Med. 166, 1471-1483 (1987).

8. Panja, A., Blumberg, R.S., Balk, S.P. \& Mayer, L. CD1d is involved in T cell-intestinal epithelial cell interactions. J. Exp. Med. 178, 1115-1119(1993).

9. Allez, M., Brimnes, J., Dotan, I. \& Mayer, L. Expansion of $\mathrm{CD}^{+} \mathrm{T}$ cells with regulatory function after interaction with intestinal epithelial cells. Gastroenterology 123,1516-1526 (2002)

10. Dotan, I., Allez, M., Nakazawa, A., Brimnes, J., Schulder-Katz, M. \& Mayer, L. Intestinal epithelial cells from inflammatory bowel disease patients preferentially stimulate CD4 ${ }^{+} \mathrm{T}$ cells to proliferate and secrete interferongamma. Am. J. Physiol. Gastrointest. Liver Physiol. 292, G1630-G1640 (2007).

11. Panja, A., Siden, E. \& Mayer L. Synthesis and regulation of accessory/proinflammatory cytokines by intestinal epithelial cells. Clin. Exp. Immunol. 100, 298-305 (1995)

12. Chang, E.B., Musch, M.W. \& Mayer, L. Interleukin 1 and 3 stimulate anion secretion in chicken intestine. Gastroenterology 98, 1518-1524 (1990).

13. Toy, L., Yio, X.Y., Lin, A., Honig, S. \& Mayer, L. Defective expression of gp180, a novel CD8 ligand on intestinal epithelial cells, in inflammatory bowel disease. J. Clin. Invest., 100, 2062-2071 (1997).

14. Nakazawa, A. et al. The expression and function of costimulatory molecules B7h and B7-H1 on colonic epithelial cells. Gastroenterology 126, 1347-1357 (2004).

15. Shang, L. et al. Toll-like receptor signaling in small intestinal epithelium promotes B-cell recruitment and IgA production in lamina propria. Gastroenterology 135, 529-538 (2008).

16. Shang, L. et al. Expression of the chemokine binding protein M3 promotes marked changes in the accumulation of specific leukocytes subsets within the intestine. Gastroenterology 137, 1006-1018 (2009). 